Acta Mechanica Slovaca 16 (1):52-65, 2012 DOI: 10.2478/v10147-012-0006-7

(0) 2012 VersitaOpen Ltd. All rights reserved.

* Corresponding author

E-mail address:tbalaw@przedupl

(Dr. Ing. Tadeusz Balawender, PhD.)

Article information

Article history: AMS-Volume16-No.1-00142-12

Received 14 December 2011

Accepted 15 March 2012

\section{Fully Coupled Thermo-Mechanical Analysis During Braking Process}

\author{
Ali Belhocine ${ }^{a *}$, Mostefa Bouchetara ${ }^{a}$ \\ aDepartment of Mechanical Engineering, USTO Oran University,L.P 1505 El -Mnaouer, USTO 31000 Oran, Algeria
}

\section{KEY WORDS}

Brake discs, pads, Heat flux, Heat transfer coefficient, Von Mises stress, Contact pressure.

\begin{abstract}
The main purpose of this study is to analysis the thermomechanical behavior of the dry contact between the brake disc and pads during the braking phase. The simulation strategy is based on softawe ANSYS11. The modeling of transient temperature in the disk brake is actually used to identify the factor of geometric design of the disk to install the ventilation system in vehicles. The thermal-structural analysis is then used coupling to determine the deformation established and the Von Mises stresses in the disk, the contact pressure distribution in pads. The results are satisfactory compared to those found in the literature.
\end{abstract}

\section{Introduction}

The braking process is in fact the matter of energy balance. The aim of braking system is to transform mechanical energy of moving vehicle into the some other form, which results by decreasing of vehicle speed. The kinetic energy is transformed into the thermal energy, by using the dry friction effects and, after that, dissipated into the surroundings [1].

In 2002, Nakatsuji et. Al [2], did a study on the initiation of hair-like cracks which formed around small holes in the flange of one-piece discs during overloading conditions. The study showed that thermally induced cyclic stress strongly affects the crack initiation in the brake discs. In order to show the crack initiation mechanism, the temperature distribution at the flange had to be measured. Using the finite element method, the temperature distribution under overloading was analyzed. 3D unsteady heat transfer analyses were conducted using ANSYS. A 1/8 of the one piece disc was divided into finite elements, and the model had a half thickness due to symmetry in the thickness direction. Valvano and Lee in 2000 [3] did a study on the technique to determine the thermal distortion of a brake rotor. The severe thermal distortion of a brake rotor can affect important brake system characteristics such as the system response and brake judder propensity. As such, the accurate prediction of thermal distortions can help in the designing of a brake disc. Analytical solutions to a boundaryvalue problem of heat conduction for friction pairs consisting of the half-space sliding (braking at uniform retardation) on a surface of the strip deposited on a semi-infinite foundation and the strip sliding on a surface of the homogenous half-space,are obtained. For materials of the frictional system: cast iron - metal ceramics-steel and metal ceramics-cast iron, evolutions and distributions on depth from the surface of friction for temperatures are studied by Yevtushenko and Kuciej [4],.The solutions to two heat 
conduction problems with frictional heating during braking with a uniform retardation were obtained in a paper by Yevtushenko and Kuciej [5] for both a tribosystem consisting of a half-space sliding on a surface of a strip deposited on a semiinfinite foundation (three-element system) and for a two-element system consisting of a plane-parallel strip and a half-space. Using the non-stationary temperature field obtained by Yevtushenko and Kuciej [6], we find the solution to distributions of quasi-static thermal stresses. The solution determines the thermal stresses in the tribosystems, both in the heating phase during braking and in the cooling phase after a stop.

In this work, we will make a modeling of the thermomechanical behavior of the dry contact between the discs of brake pads at the time of braking phase; the strategy of calculation is based on the software Ansys 11 [7]. This last is elaborate mainly for resolution of the complex physical problems. The numerical simulation of the coupled transient thermal and stress field is carried out by sequentially thermal-structural coupled method based on Ansys.

\section{Heat Flux Entering the Disc}

The brake disk assumes the most part of the heat, usually more than 90\% [8] through the effective contact surface of the friction coupling. Considering the complexity of the problem and average data processing limited, one replaced the pads by their effect, represented by an entering heat flux ( Figure.1)

The initial heat flux $q_{0}$ entering the disc is calculated by the following formula [9]

$q_{0}=\frac{1-\Phi}{2} \cdot \frac{m \cdot g \cdot v \cdot z}{a \cdot A_{d} \cdot s_{p}}$

Where $z=a / g$ : Braking effectiveness, $a$ : Deceleration of the vehicle $\left[\mathrm{ms}^{-2}\right], \varnothing$ : Rate distribution of the braking forces between the front and rear axle, $A_{d}$ : Disc surface swept by a brake pad $\left[\mathrm{m}^{2}\right], v_{0}$ : Initial speed of the vehicle $\left[\mathrm{ms}^{-1}\right] \varepsilon_{p}$ : Factor load distribution of the on the surface of the disc., $m$ : Mass of the vehicle $[\mathrm{kg}], \mathrm{g}$ : Acceleration of gravity (9.81) $\left[\mathrm{ms}^{-2}\right]$.

The loading corresponds to the heat flux on the disc surface. The dimensions and the parameters used in the thermal calculation are recapitulated in
Table 1.

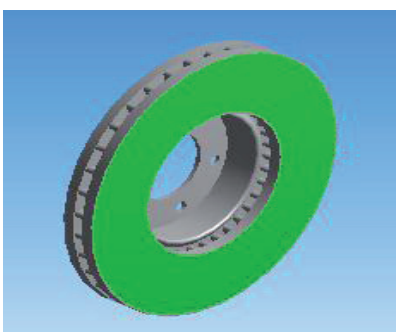

Fig. 1: Application of flux

Table 1: Geometrical Dimensions and application parameters of automotive braking = Sulfates, TC = Total Cyanides, TI = Total Iron, SD - Standard deviation.

\section{Item} Values

\begin{tabular}{|l|l|}
\hline Inner disc diameter, $\mathrm{mm}$ & 66 \\
\hline Outer disc diameter, $\mathrm{mm}$ & 262 \\
\hline Disc thickness $(\mathrm{TH}), \mathrm{mm}$ & 29 \\
\hline Disc height $(\mathrm{H}), \mathrm{mm}$ & 51 \\
\hline Vehicle mass, $\mathrm{kg}$ & 1385 \\
\hline Initial speed $\mathrm{v}_{0^{\prime}} \mathrm{km} / \mathrm{h}$ & 28 \\
\hline Deceleration, $\mathrm{m} / \mathrm{s}^{2}$ & 8 \\
\hline Effective rotor radius Rrotor, $\mathrm{mm}$ & 100.5 \\
\hline Rate distribution of the braking forces $\phi, \%$ & 20 \\
\hline Factor of charge distribution on the disc $\varepsilon_{\mathrm{p}}$ & 0.5 \\
\hline Surface disc swept by the pad $\mathrm{A}_{\mathrm{d}^{\prime}} \mathrm{mm}^{2}$ & 35993 \\
\hline
\end{tabular}

The disc material is gray cast iron ( GFC) with high carbon content (Gotowicki et al.2005), with a good thermophysical characteristics and the brake pad has an isotropic elastic behavior whose thermomechanical characteristics adopted in this simulation of the two parts are recapitulated in Table 2.

Table 2: Thermoelastic properties used in simulation.

\begin{tabular}{|l|l|l|}
\hline Material Properties & Pad & \multicolumn{1}{l|}{ Disc } \\
\hline Thermal conductivity, $\mathrm{k}\left(\mathrm{W} / \mathrm{m}^{\circ} \mathrm{C}\right)$ & 5 & 57 \\
\hline Density, $\mathrm{\rho}(\mathrm{kg} / \mathrm{m} 3)$ & 1400 & 7250 \\
\hline Specific heat, $\mathrm{c}\left(\mathrm{J} / \mathrm{Kg}^{\circ} \mathrm{C}\right)$ & 1000 & 460 \\
\hline Poisson's ratio, $\mathrm{U}$ & 0,25 & 0,28 \\
\hline Thermal expansion, $\mathrm{a}\left(10-6 /{ }^{\circ} \mathrm{C}\right)$ & 10 & 10,85 \\
\hline Elastic modulus, $\mathrm{E}(\mathrm{GPa})$ & 1 & 138 \\
\hline Coefficient of friction, $\mu$ & 0,2 & 0,2 \\
\hline Operation Conditions & Pad & Disc \\
\hline Angular velocity, $\omega$ & & 157.89 \\
\hline Hydraulic pressure, $\mathrm{P}(\mathrm{MPa})$ & & 1 \\
\hline
\end{tabular}




\section{Modeling in ANSYS CFX}

The solution scheme employees the $k-\varepsilon$ model with scalable wall function and sequential load steps. For the preparation of the mesh of CFD model, one defines initially, various surfaces of the disc in ICEM CFD, we used a linear tetrahedral element with 30717 nodes and 179798 elements. In order not to weigh down calculation, an irregular mesh is used in which the meshs are broader where the gradients are weaker (not-uniform mesh)

The CFD models were constructed and were solved using ANSYS-CFX software package. The models employ periodic boundary conditions on the segmented sides; and the radial and axial lengths of the air domain surrounding the disc. The disc is modeled attached to an adiabatic shaft whose axial length spans that of the domain. The air around the disc is considered at $T_{\infty}=20^{\circ} \mathrm{C}$ and open boundaries with zero relative pressure were used for the upper, lower and radial ends of the domain (Fig. 2).

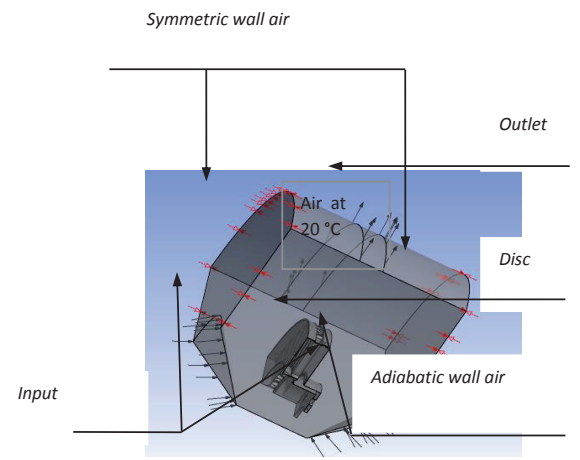

Fig. 2: Brake disc CFD model

The values of the exchange coefficient will be taken average values calculated by the minimal and maximum values obtained using ANSYS CFX POST as it east indicates on Fig. 3.

\section{a) Results of convection heat transfer coefficient $h$}

Figs. 4 and 5 respectively give the variation of exchange coefficient ( $h$ ) for various surfaces components the full and ventilated disc. One then obtains beams of curves in the transitory mode of flow having the same form and decrease about the braking time ( $t=3,5 \mathrm{~s}$ ). One observes that in the case of ventilated disc, the values of (h) are large that of the full disc what characterizes the fast model of cooling.

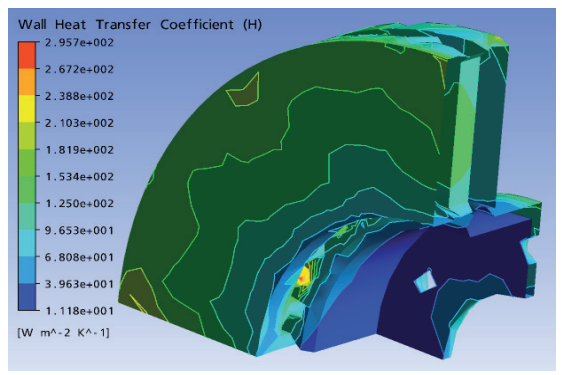

Fig. 3: Distribution of heat transfer coefficient on a ventilated disc in the stationary case (FG 15).

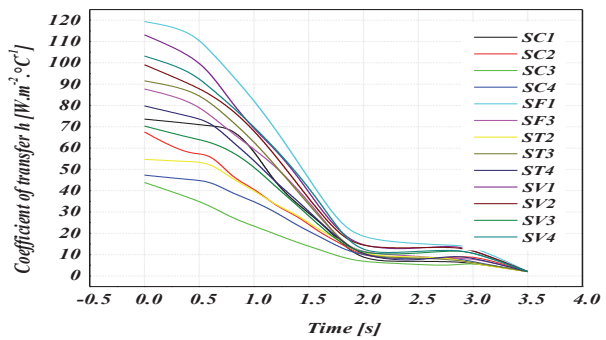

Fig. 4: Variation of heat transfer coefficient (h) of various surfaces for a full disc in the non stationary case (FG 15).

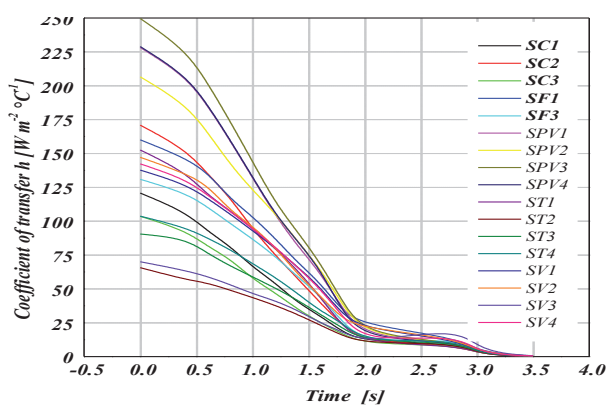

Fig. 5: Variation of heat transfer coefficient (h) of various surfaces for a ventilated disc in transient case (FG 15).

The comparison between Figs. 4 and 5 concerning the variation of heat transfer coefficient in the non stationary mode for the two types of design of the full and ventilated disc, one notes that the introduction of the ventilation system influences directly the value of this coefficient for same surface what is logically significant because this mode of ventilation intervenes in the reduction in the difference in temperature wall-fluid.

\section{Initial and Boundary Conditions}

The boundary conditions are introduced into module ANSYS Workbench [ Multiphysics], by choosing the mode of simulation first of all (permanent or transitory), and by defining the physical 
properties of materials. These conditions constitute the initial conditions of our simulation. After having fixed these parameters, one introduces a boundary condition associated with each surface

- Total time of simulation $=45[\mathrm{~s}]$,

- Increment of initial time $=0.25$ [s],

- Increment of minimal initial time $=0.125$ [s],

- Increment of maximal initial time $=0.5[\mathrm{~s}]$,

-Initial temperature of the disc $=60\left[{ }^{\circ} \mathrm{C}\right]$,

- Materials: Grey Cast iron FG 15,

- Convection: One introduces the values of heat transfer coefficient (h) obtained for each surface in the shape of a curve (Figs.4-5),

- Flow: One introduces the values obtained of flow entering by code CFX.

\section{Results and Discussions \\ 5.1 Influence of construction of the disc}

Fig.6 shows the variation in the temperature according to time during a simulation. From the first step, the variation in the temperature shows a great growth which is due to the speed of the physical course of phenomenon during a braking phase, namely friction, plastic micro distortion of contact surfaces ...
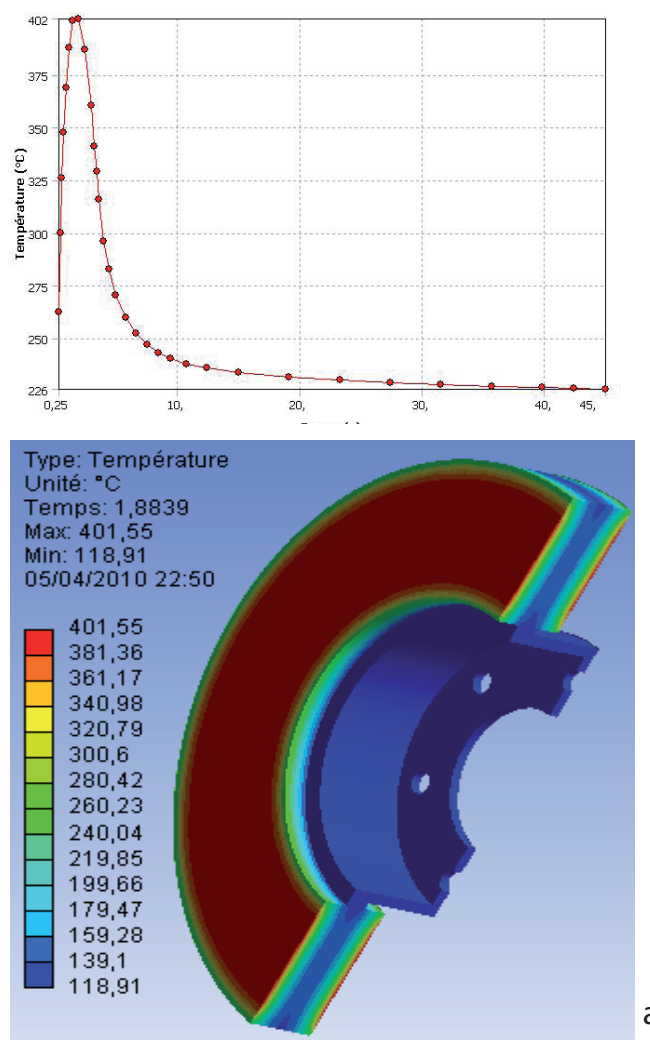
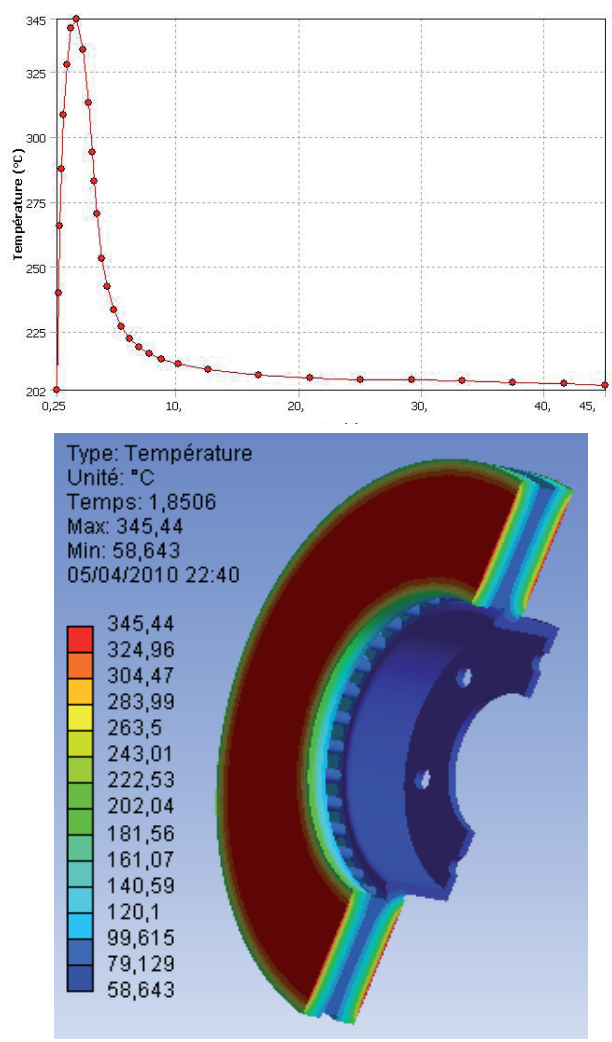

b)

Fig. 6: Temperature distribution of a full (a) and ventilated disc (b) of cast iron (FG 15).

For the full disc, the temperature reaches its maximum value of $401,55^{\circ} \mathrm{C}$ at the moment $\mathrm{t}=1,8839 \mathrm{~s}$, then it falls quickly to 4,9293 s, as of this moment and until the end time of simulation ( $t=45 \mathrm{~s}$ ), the variation in the temperature becomes slow. It is noted that the interval [0-3,5 s] represents the phase of forced convection. From the latter, one is in the case of the free convection until the end of the simulation. In the case of ventilated disc, one observes that the temperature of the falls disc approximately $60^{\circ} \mathrm{C}$ compared to the first case. It is noted that the ventilation in the design of the disc brake gives a better system of cooling.

\section{Coupled Thermo-Mechanical Analysis 6.1 FE model and boundary conditions}

The numerical simulations using the ANSYS finite element software package were performed in this study for a simplified version of a disc brake system which consists of the two main components contributing to squeal the disc and the pads. The various boundary conditions in embedded cona) figurations are imposed on the model (disc-pad), 
taking into account its environment direct, are respectively ,the simple case as shown in Fig. 7 . The initial temperature of the disc and the pads is $20^{\circ} \mathrm{C}$ and the surface convection condition is applied at all surfaces of the disc with the values of the exchange coefficient calculated previously and the convection coefficient (h) of $5 \mathrm{~W} / \mathrm{m}^{2} .{ }^{\circ} \mathrm{C}$ is applied at the surface of the two pads. The heat flux into the brake disc during a braking process can be calculated by the formula described in the first part. The FE mesh is generated using three-dimensional tetrahedral element with 10 nodes (solid 187) for the disc and brake pads. There are about 185901 nodes and 113367 elements are used (Fig. 8). The thermal coupling will be carried out by the thermal condition at a temperature nonuniform all takes the thermal environment of the model of it, For this reason, the order "thermal condition" will be used to deal with the thermomechanical coupled problem and to manage the transient state.

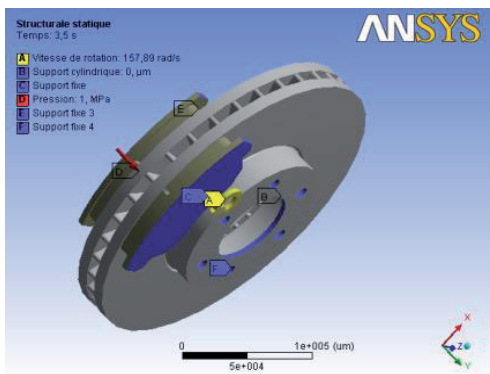

Fig. 7: Boundary conditions and loading imposed on the discpads.

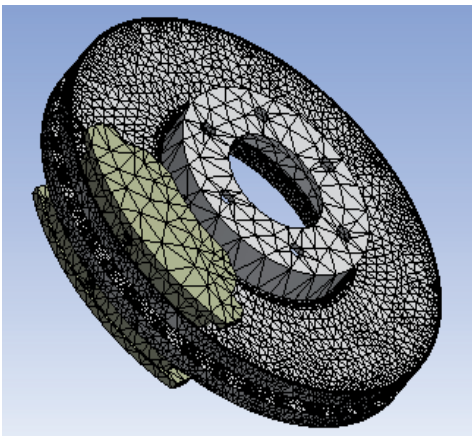

Fig. 8: Refined mesh of the model.

\subsection{Thermal deformation}

Fig. 9 gives the distribution of the total distortion in the whole (disc-pads) for various moments of simulation. For this figure, the scale of deformation values varies from $0 \mu \mathrm{m}$ to $284,55 \mu \mathrm{m}$. The value of maximum displacement recorded during this simulation is at the moment $t=3,5 \mathrm{~s}$ which corresponds to the braking time. One observes a strong distribution which increases with time on the friction tracks and the crown external and the cooling fins of the disc. Indeed, during a braking, the maximum temperature depends almost entirely on the storage capacity of heat of disc (on particular tracks of friction) this deformation will generate a dissymmetry of the disc following the rise of temperature what will cause a deformation in the shape of an umbrella.

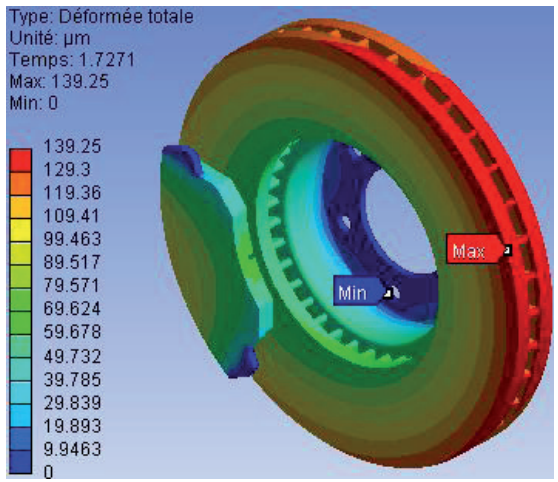

(a) $t=1,7271 \mathrm{~s}$

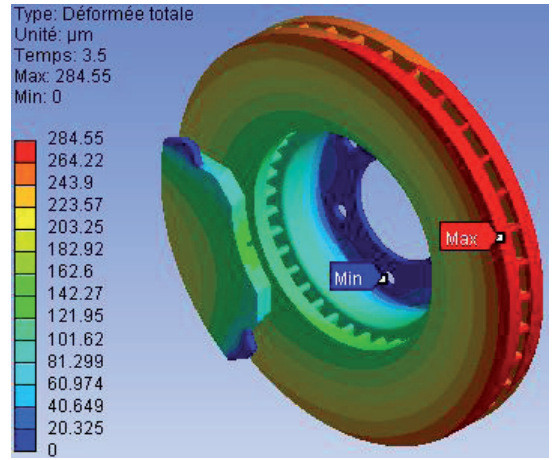

(b) $t=3,5 \mathrm{~s}$

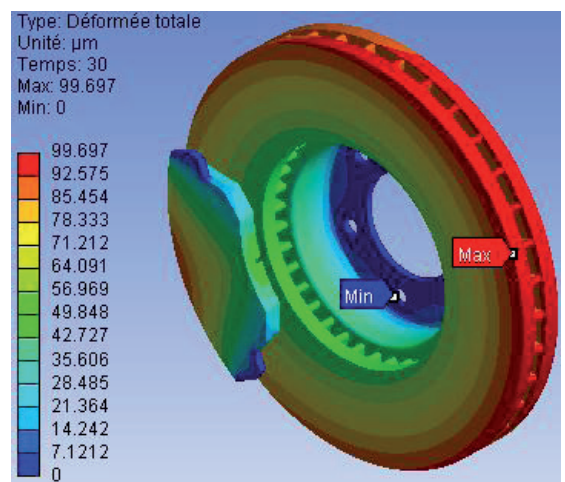

(c) $t=30 \mathrm{~s}$ 


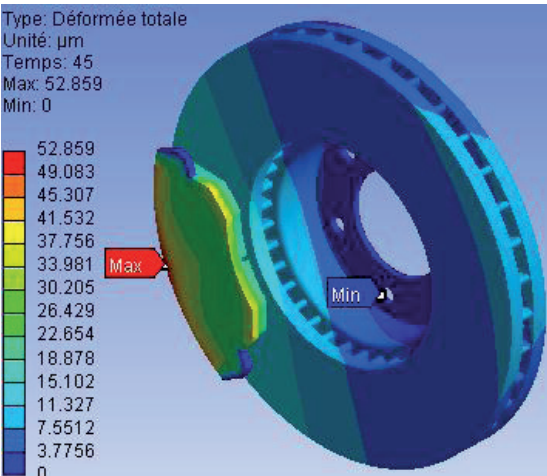

(d) $\mathrm{t}=45 \mathrm{~s}$

Fig. 9: Total distortion distribution

\subsection{Von Mises stress distribution}

Fig. 10 presents the Von Mises stress distribution to various moments of simulation, the scale of values varies from $0 \mathrm{MPa}$ to $495,56 \mathrm{MPa}$. The maximum value recorded during this simulation of the thermomechanical coupling is very significant that, that obtained with the assistance in the mechanical analysis dryness under the same conditions.

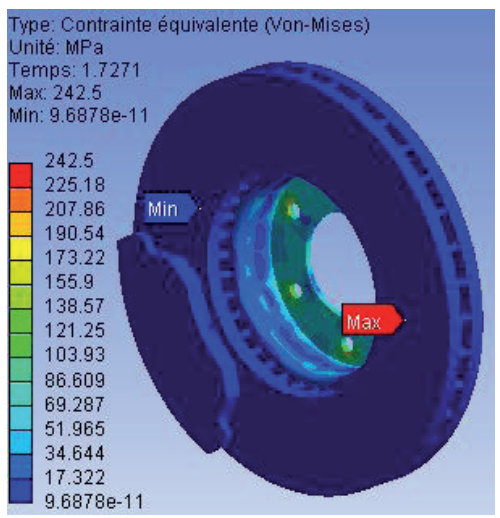

(a) $t=1,7271 \mathrm{~s}$

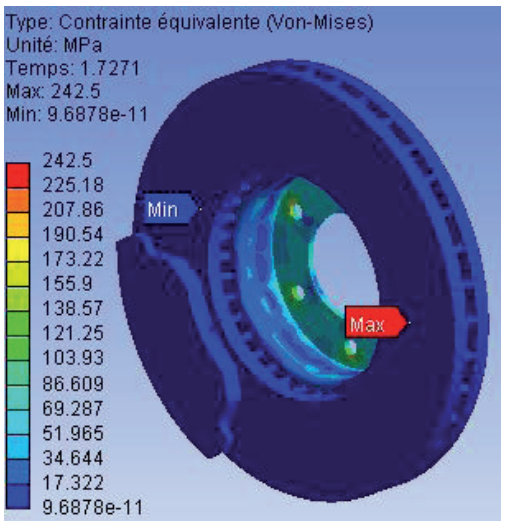

(b) $t=3,5 \mathrm{~s}$

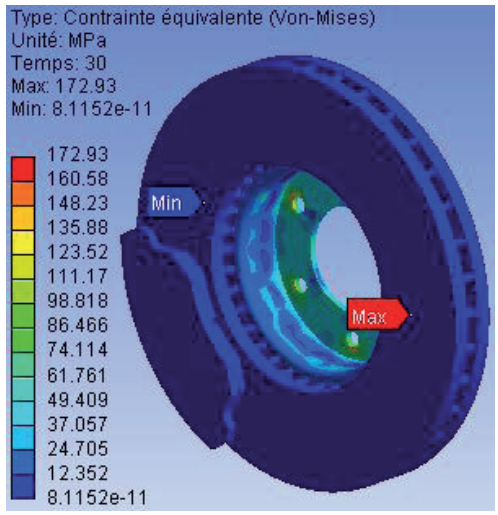

(c) $t=30 \mathrm{~s}$

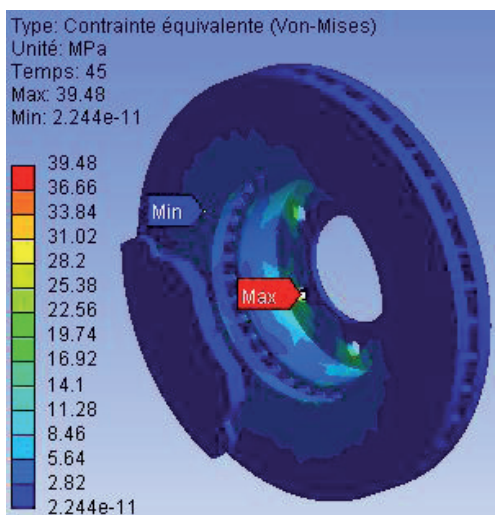

(d) $\mathrm{t}=45 \mathrm{~s}$

Fig. 10: Von Mises stress distribution.

One observes a strong constraint on the level of the bowl of the disc.Indeed, the disc is fixed to the hub of the wheel by screws preventing its movement.And in the present of the rotation of the disc and the requests of torsional stress and sheers generated at the level of the bowl which being able to create the stress concentrations. The repetition of these requests will involve risks of rupture on the level of the bowl of the disc.

\section{$\mathbf{6 . 4}$ Contact pressure}

8 Fig.11 shows the contact pressure distribution in the friction interface of the inner pad taken for at various times of simulation.For this distribution the scale varies from $0 \mathrm{MPa}$ to $3,3477 \mathrm{MPa}$ and reached a value of pressure at the moment $t=3,5 \mathrm{~s}$ which corresponds to the null rotational speed.It is also noticed that the maximum contact pressure is located on the edges of the pad of the entry and goes down towards the exit from the area from friction. This pressure distribution is almost symmetrical compared to the groove and it has the same ten- 
dency as that of the distribution of the temperature because the highest area of the pressure is located in the same sectors. Indeed, at the time of the thermomechanical coupling $3 d$, the pressure carries out

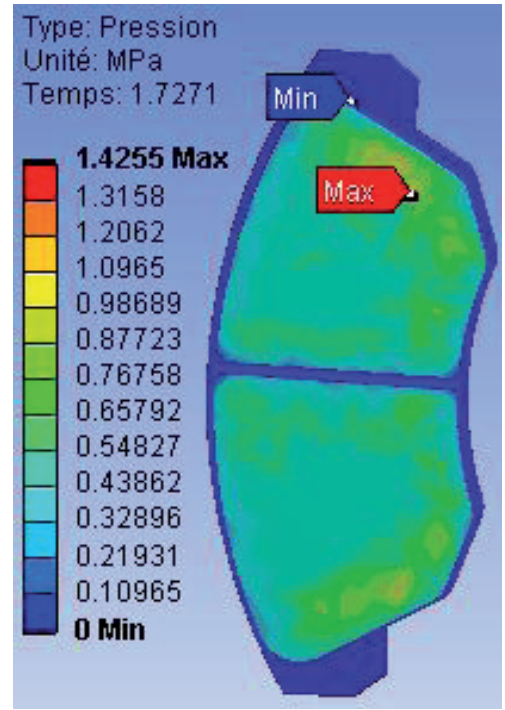

(a) $\mathrm{t}=1,7271 \mathrm{~s}$

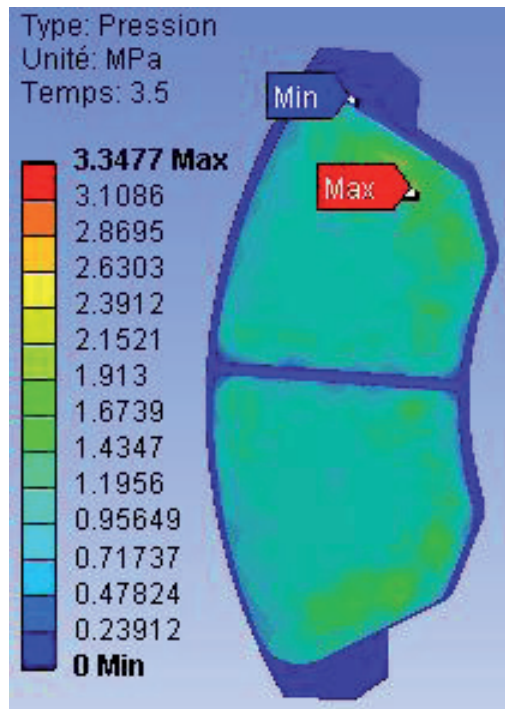

(b) $t=3,5 \mathrm{~s}$

\section{Conclusion}

In this publication, we presented the thermomechanical behavior analysis of the dry contact between the disc and brake pads during the braking process; the modeling is based on the ANSYS software 11.0. We have shown that the ventilation system plays an important role in cooling disks and provides a good high temperature resistance.

The analysis results showed that, a temperature and to lead to the not-axisymmetric field of the temperature. This last affects thermal dilation and leads to a variation of the contact pressure distribution.

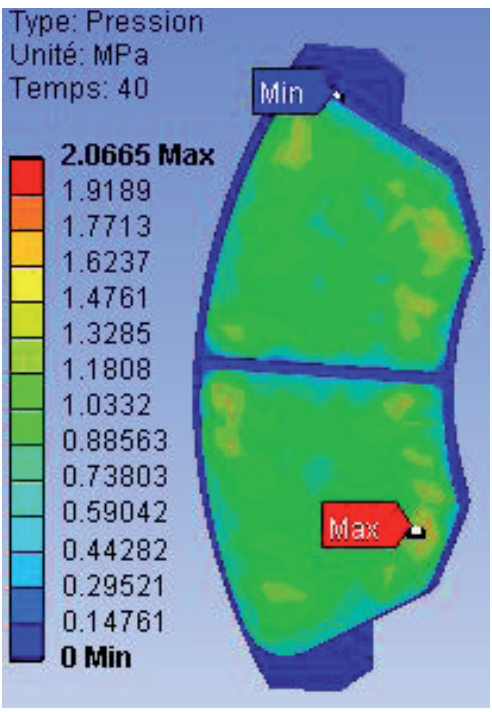

(c) $t=30 \mathrm{~s}$

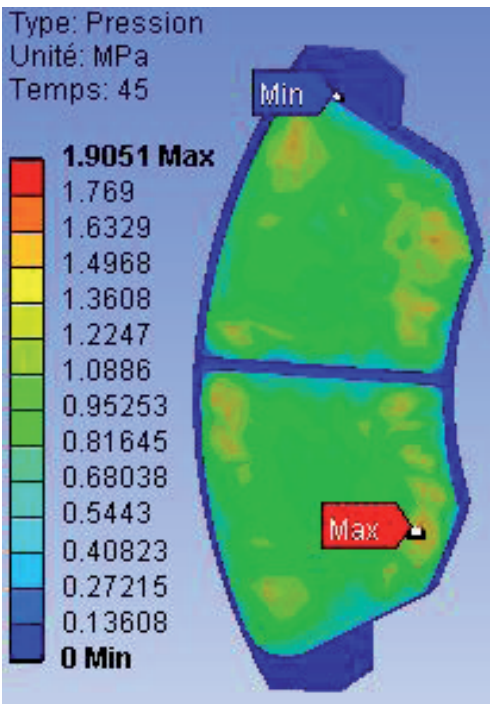

(d) $\mathrm{t}=45 \mathrm{~s}$

Fig. 11: Contact pressure distribution in the inner pad.

stress fields in the braking process phase of were fully coupled. The temperature, the Von Mises stress and the total deformations of the disc and the contact pressure distribution in the pads increases as the thermal stresses are additional to mechanical stress which causes the crack propagation and fracture of the bowl and wear of the disc and brake pads. Regarding the calculation results, we can say that they are satisfactory commonly found in the literature 
investigations. It would be interesting to solve the thermo-mechanical problem of disc brakes with an experimental study to validate the numerical results.

\section{Acknowledge}

This paper was prepared with the support of grant project VEGA 1/0543/10.

\section{References}

[1] Milenković, P.D.et.al..2010: The influence of brake pads thermal conductivity on passanger car brake system efficiency ,Thermal Science: , Vol. 14, Suppl., pp. S221- S230.

[2] Nakatsuji T, Okubo K, Fujii T, Sasada M, Noguchi Y, 2002. Study on Crack Initiation at Small Holes of One- piece Brake Discs. Society of Automotive Engineers, Inc 2002-01-0926.

[3] Valvano T, Lee K,2000. An Analytical Method to Predict Thermal Distortion of a Brake Rotor. Society of Automotive Engineers, Inc 2000-01-0445.

[4] Yevtushenko A.,Kuciej M.,2010,Two heat conduction problems with frictionalheating during braking, J. Theoret. Appl. Mech., 48, 3, pp. 605-621, Warsaw 2010.

[5] TYevtushenko A.,Kuciej M.,2010,Two heat conduction problems with frictional heating during braking, J. Theoret. Appl. Mech., 48, 2, pp. 367-380, Warsaw 2010.

[6] Zhang L, Yang Q, Weichert D, Tan N. Simulation and Analysis of Thermal Fatigue Based on Imperfection Model of Brake Discs, Beijing Jiaotong University, PAMM • Proc. Appl. Math. Mech. 9, 533 - 534 (2009).

[7] Cruceanu, C., Frâne pentru vehicule feroviare ( Brakes for railway vehicles), Ed. MATRIXROM, Bucureşti, 2007, ISBN 978-973-755-200-6, 388 pag.

[8] Reimpel J.:Technologie de freinage. Vogel Verlag, Würzburg, 1998.

[9] Gotowicki,Pier Francesco ; Nigrelli , Vinzenco ; Mariotti, Gabriele Virzi. 2005. Numerical and experimental analysis of a pegs-wing ventilated disk brake rotor, with pads and cylinders, 10 th EAEC European Automotive Congress Paper EAEC05YUAS04- P 5, June 2005. 